\title{
Colonoscopic diagnosis of rectal perforation by foreign body
}

\author{
Ashok Y. Kshirsagar, N. R. Nangare, Mayank A. Vekariya, Akshay S. Pednekar \\ Department of Surgery, Krishna Institute of Medical Sciences University, Karad, Satara, Maharashtra, India
}

\begin{abstract}
A foreign body in the rectum is not as common as other parts of the body and presents a dilemma for management. Variety of foreign bodies have been found into the rectum such as turnip, stick, tumbler, paper pot, screw driver, live shell, glass bottle, vibrator, door handle, electric bulb, candles, and fruits. Some are introduced for diagnostic or therapeutic purpose like thermometer, enema tubes, disposable enema tips, irrigation catheters. Emergency department procedures include rectal examination, proctoscopy, and abdominal radiography. Although foreign bodies can be removed in the emergency department in about two out of three cases, some still require a laparotomy and a diverting colostomy to remove the object or to treat bowel perforation.

Key words Foreign body, rectal perforation, trans-anal rectal injuries
\end{abstract}

\section{Introduction}

In recent years, we have seen an increasing incidence of complications of foreign bodies inserted into the rectum. The vast majority of objects are inserted by self-introduction in children, psychiatric patients, in the victim of the assault or as a result of sexual gratification. Iatrogenic foreign bodies include thermometers, enema tips and catheters. ${ }^{[1]}$ Here is the case, first of its type, where the "pen" was used to relieve constipation and presented as a foreign body in the rectum causing rectal perforation.

\section{Case Report}

A 55-year-old male presented to our hospital with complaints of pain abdomen and constipation since 3 days. He was a known case of diabetes mellitus and hypertension for which he was on oral medication; he also gave a history of chronic

\begin{tabular}{|l|c|}
\hline \multicolumn{2}{|c|}{ Access this article online } \\
\hline \multirow{2}{*}{$\begin{array}{l}\text { Website: } \\
\text { www.jdeonline.in }\end{array}$} & Quick Response Code \\
\hline DOI: & \\
10.4103/0976-5042.144831 & \\
\hline
\end{tabular}

constipation. Pain started as sudden onset in the lower abdomen which later became generalized, of moderate severity, continuous in nature, nonradiating, associated with fever, nausea and constipation. On taking detailed history, patient told that he habitually used a pen to relieve his constipation and 3 days back when he used a pen to relieve constipation he was not able to retrieve it and the pen was retained per rectum. His vitals were stable and laboratory investigations were within the normal limits. Abdomen was distended with a generalized tenderness and guarding with absent bowel sounds. On per rectal examination, foreign body could not be felt. Radiograph showed free gas under the domes of the diaphragm. After initial resuscitation exploratory laparotomy was performed. On examination, stomach, duodenum, small gut and other viscera were normal. Appendix, caecum, and large bowel were also healthy. However, there was a perforation of rectum from where the pen was projecting into the peritoneal cavity [Figures 1 and 2]. The pen was removed, and perforation was sutured in two layers, a proximal colostomy was established and abdomen was closed with drain [Figure 3]. Postoperative period of the patient was uneventful, and patient was discharged on $11^{\text {th }}$ postoperative day.

\section{Discussion}

The presentation of patients with rectal foreign body varies from asymptomatic case to diffuse peritonitis depending on the 


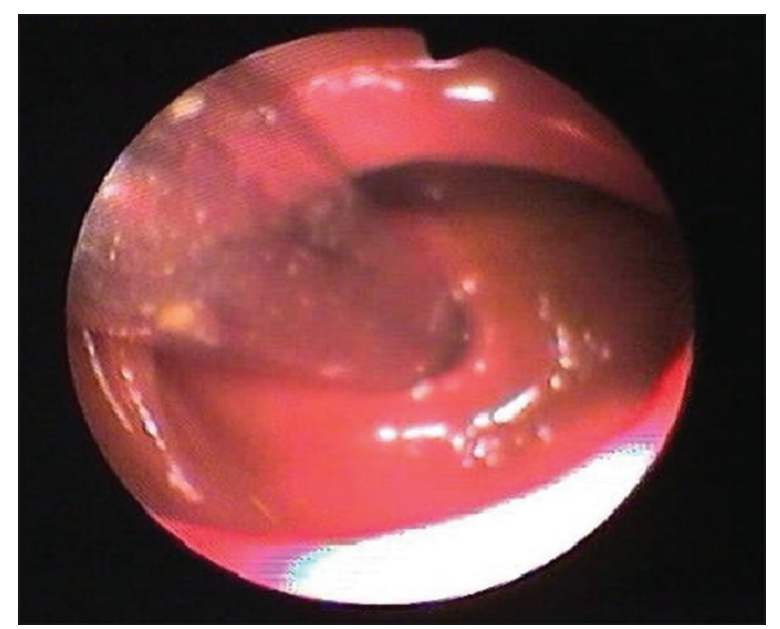

Figure 1: Colonoscopic view of rectal foreign body-pen

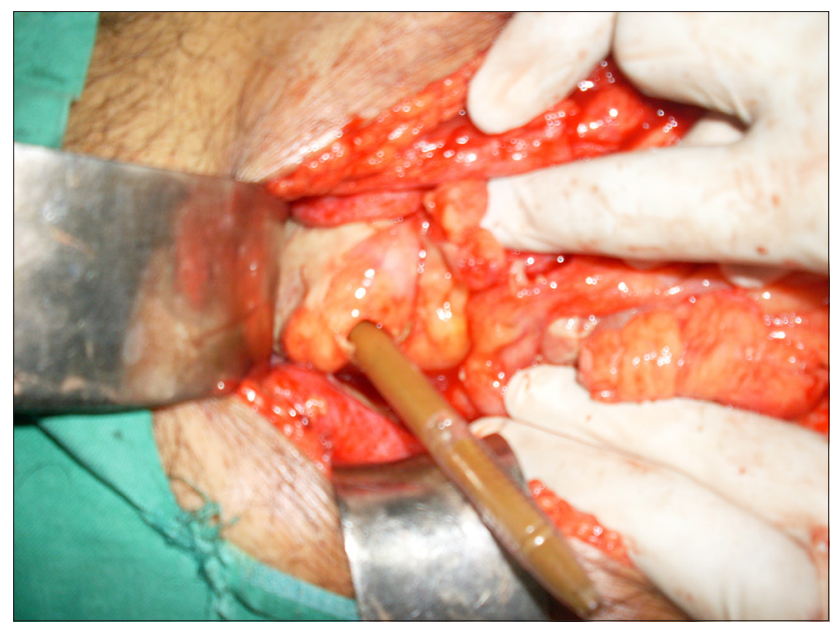

Figure 2: Intraoperative pen in perforated rectum

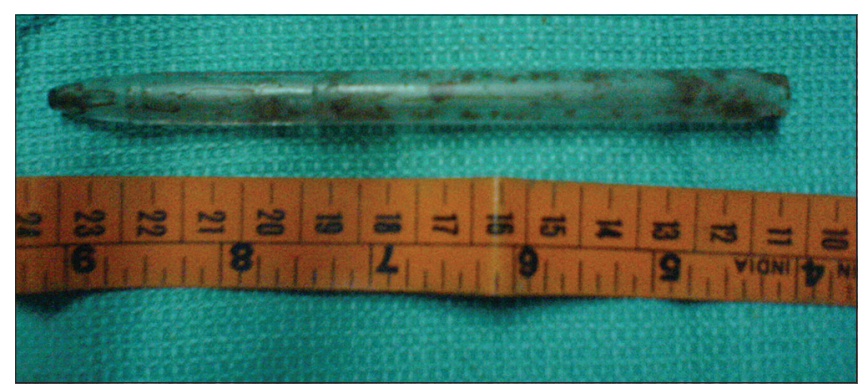

Figure 3: Postoperative specimen of pen

type of the foreign body, time of insertion, the way of insertion and the presence or absence of nonprofessional intervention to retrieve them. Patients may delay their presentation due to embarrassment, fear of stigmatization, or ignorance regarding the seriousness of their symptoms. ${ }^{[2]}$ A detailed clinical history and physical examination are essential for the diagnosis and management of these lesions. ${ }^{[3]}$

Anorectal simulation and penetration is a relatively common sexual practice. Digital and penile penetrations are the most common forms. A segment of the homosexual population practices fist fornication, a technique that involves the insertion of fist and arm into the anorectum. This activity can result in severe injury to the anal sphincter and perforation of the rectum and colon. ${ }^{[4]}$ Anorectal foreign body is no longer a medical oddity, rather it is encountered frequently. Here is the case, first of its type, where the "pen" was used to relieve constipation and presented as a foreign body in the rectum causing rectal perforation.

A laparotomy for removal of the foreign body in the rectum is indicated in patients with overt peritonitis or pelvic sepsis that results from perforation of the bowel. The principles of repair or resection of the injured bowel, fecal diversion, cleansing of the distal bowel and presacral drainage have been well established. ${ }^{[5]}$

Nevertheless, there has been controversy regarding the management of patients with impacted foreign bodies without complication. Some authors propose laparotomy with milking down and retracting the object transanally or through a colostomy if the object is too big to be removed from below. ${ }^{[6]}$ However now, the flexible fiberoptic colonoscope, has been utilized in such cases with a considerable successful rate. ${ }^{[7]}$ It was even suggested that colonoscopic retrieval could be considered as the first step in the management of these patients.

\section{Conclusion}

Foreign bodies in the rectum represent a management difficulty. Most of the uncomplicated rectal foreign bodies could be simply extracted in the operating room with adequate anesthesia, but fiberoptic colonoscopic extraction provided an alternative choice. Open surgery should be reserved only for those patients with overt peritonitis or pelvic sepsis.

\section{References}

1. Jatal SN. Colorectal foreign bodies and principles of its management. Indian J Surg 1995;57:233-5.

2. Spears KL, Hutson HR, Atluri SP. Rectal perforation following manual-anal intercourse. Acad Emerg Med 1995;2:852-3.

3. Ruiz del Castillo J, Sellés Dechent R, Millán Scheiding M, Zumárraga Navas P, Asencio Arana F. Colorectal trauma caused by foreign bodies introduced during sexual activity: Diagnosis and management. Rev Esp Enferm Dig 2001;93:631-4.

4. Schecter WP, Albo RJ. Removal of rectal foreign body. Mastery of Surgery. $3^{\text {rd }}$ ed., Vol. 2. 1996. p. 1555-9.

5. Nehme Kingsley A, Abcarian H. Colorectal foreign bodies. Management update. Dis Colon Rectum 1985;28:941-4.

6. Eftaiha M, Hambrick E, Abcarian H. Principles of management of colorectal foreign bodies. Arch Surg 1977;112:691-5.

7. Ahmed A, Cummings SA. Novel endoscopic approach for removal of a rectal foreign body. Gastrointest Endosc 1999;50:872-4.

How to cite this article: Kshirsagar AY, Nangare NR, Vekariya MA, Pednekar AS. Colonoscopic diagnosis of rectal perforation by foreign body. J Dig Endosc 2014;5:69-70.

Source of Support: Nil, Conflict of Interest: None declared. 